\title{
A TAREFA DE ENSINAR DIREITO NO CAMPO DAS POLÍTICAS PÚBLICAS - O DESAFIO DE INTEGRAR UMA COMUNIDADE EPISTÊMICA INTERDISCIPLINAR ${ }^{1}$
}

\section{THE TASK OF TEACHING LAW IN A FACULTY OF PUBLIC POLICY - THE CHALLENGE OF INTEGRATING AN INTERDISCIPLINARY EPISTEMIC COMMUNITY}

\author{
ESTER GAMMARDELLA RIZZI ${ }^{2}$ \\ GUSTAVO BAMBINI ${ }^{3}$
}

RESUMO: O pressuposto que orienta a montagem dos cursos de graduação no campo das políticas públicas é claro: para se formar um bom profissional ou um bom pesquisador da área é necessário fazê-lo transitar por diversos campos de conhecimento que, historicamente, se constituíram afastados uns dos outros. $\mathrm{O}$ desafio é como compreender e praticar a interdisciplinaridade intrínseca a essa proposta. Mais especificamente, como fazer com que a transição constante e necessária entre diversos campos de saber não resulte, ao final, em uma formação deficiente, quando considerada do ponto de vista de cada disciplina particular, e fragmentada, quando considerada em seu conjunto? Para indicar o núcleo do desafio da formação interdisciplinar, utilizamos o conceito de "comunidade epistêmica", que se caracteriza pelo fato de que seus membros compartilham, em maior ou menor medida: a) uma linguagem comum, dotada de certos conceitos que se supõem aptos a descrever os objetos de estudo do campo, mas que, bem considerados, estão também construindo esses objetos de estudo; b) uma avaliação comum acerca de quais são os problemas relevantes a serem resolvidos com relação a esses objetos; c) tendência a uniformizar certas crenças básicas, pré-teóricas, que permitem estruturar o campo de estudos; d) uma visão compartilhada a respeito

\footnotetext{
${ }^{1}$ Agradecemos os comentários e as sugestões dos professores Tiago Tranjan, Maria Paula Dallari Bucci, Cristiane Kerches e Emiliano Brunet, com quem tivemos o prazer de discutir o texto.

2 Professora de Direito no curso de Gestão de Políticas Públicas da Escola de Artes, Ciências e Humanidades da USP (EACH-USP). Atualmente participa do grupo interdisciplinar "Neoliberalismo, subjetivação e resistências" vinculado ao Instituto de Estudos Avançados da USP. Mestre e Doutora em Filosofia e Teoria Geral do Direito pela Faculdade de Direito da USP. Contato: ester.rizzi@usp.br.

${ }^{3}$ Professor de Direito no curso de Gestão de Políticas Públicas da Escola de Artes, Ciências e Humanidades da USP (EACH-USP). Doutor em Direito do Estado pela Faculdade de Direito da USP. Contato: gustavo.bambini@gmail.com.
} 
de quais são os métodos válidos, aceitáveis, para a abordagem e resolução dos problemas da disciplina (ZITO, 2001; HAAS, 1992). O desafio aos professores do campo de públicas reside no dilema entre se afastarem de suas comunidades de origem para forjar uma comunidade epistêmica própria, interdisciplinar, ou manter o vínculo com sua comunidade epistêmica de origem.

Palavras-Chave: Comunidade epistêmica; Ensino do direito; Interdisciplinaridade; Políticas públicas.

ABSTRACT: The assumption that guides the assembly of courses in the field of public policy is clear: to form a good professional or a good researcher in the area it is necessary to make it transition through several fields of knowledge that, historically, were separated from each other. The challenge is: how to understand and practice the interdisciplinarity intrinsic to this proposal? More specifically, how to make the constant and necessary transition between different fields of knowledge not result, at the end, only a deficient formation, when considered from the point of view of each particular discipline, and fragmented, when considered as a whole? To indicate the core of the challenge of interdisciplinary formation, we use the concept of "epistemic community", which is characterized by the fact that its members share, to a greater or lesser extent: a) a common language, endowed with certain concepts that are supposed to be apt describing field study objects, but which, well considered, are also constructing these study objects; b) a common assessment of what are the relevant problems to be solved with respect to these objects; c) tendency to standardize certain basic, pre-theoretical beliefs, which allow structuring the field of study; d) a shared view of what are valid, acceptable methods for addressing and solving the problems of the discipline (ZITO 2001; HAAS, 1992). The challenge of teachers of the public field lies in the dilemma of moving away from their communities of origin to forge their own interdisciplinary epistemic community, or maintaining the bond with their first epistemic community.

KeYWORDS: Epistemic community; Law Teaching; Interdisciplinarity; Public policies. 


\section{INTRODUÇÃO}

Os cursos de Gestão de Políticas Públicas, Administração Pública, Gestão Pública e outros nomes que designam as graduações do "campo de públicas" como tem sido conhecido desde a formulação das Diretrizes Curriculares Nacionais pelo Conselho Nacional de Educação do MEC em 2014 (Resolução CNE/CES n.1/2014) - são interdisciplinares. Isso significa que se espera que bacharéis em administração pública estejam "aptos a atuar como políticos, administradores ou gestores públicos na administração pública estatal e não estatal, nacional e internacional, e analistas e formuladores de políticas públicas." (art. 3o.). E, para isso, devem conhecer as áreas disciplinares da administração, do direito, da economia, da ciência política, das ciências contábeis e da sociologia (art. 5o., §1o., I).

Trata-se de proposta, portanto, marcada desde seu início pela ideia de interdisciplinaridade ${ }^{4}$. A suposição fundamental que orienta a montagem desses cursos é clara: para se formar um bom profissional ou um bom pesquisador da área, é necessário fazê-lo transitar por diversos campos de conhecimento que, historicamente, se constituíram afastados uns dos outros.

O desafio central que se coloca, então, pode ser descrito assim: como compreender a interdisciplinaridade intrínseca a essa proposta? Mais especificamente, como fazer com que a transição constante e necessária entre diversos campos de saber não resulte, ao final, apenas em uma formação deficiente, quando considerada do ponto de vista de cada disciplina particular, e fragmentada, quando considerada em seu conjunto?

No presente artigo, vamos abordar essa questão partindo de experiências concretas. Nossa estratégia será examinar, justamente, os dois aspectos que a relação entre essas duas disciplinas assume. Por um lado, certas dificuldades que resultam da maneira específica como cada uma delas constrói e aborda seu objeto. É o aspecto tenso da relação. Por outro lado, desejamos expor algumas novas possibilidades - ricas tanto do ponto de vista conceitual como metodológico - que emergem desse contato. Aqui, como veremos, a própria necessidade de transposição, ou tradução, de uma área até a outra acaba por permitir importantes ganhos teóricos e práticos. É o lado fecundo da relação. Fazer prevalecer essa

\footnotetext{
${ }^{4}$ Interdisciplinar e transdisciplinar são os termos utilizados na Resolução CNE/CES n.1/2014 do MEC para definir as características do campo de públicas. Adotaremos a terminologia fixada na referência legal por entendermos que o desafio daqueles que fazem parte do projeto de realizar um curso com essas características é exatamente ponderar em que medida as áreas disciplinares se misturam para o surgimento de um novo amálgama e em que medida deve-se preservar as características dos campos de origem, mantendo seus limites originais. Não acreditamos que essa tensão se resolva na escolha de um conceito, mas sim nas práticas daqueles que fazem parte do projeto. Para essa discussão, ver também Marques e Faria (2013).
} 
fecundidade é, em grande medida, um dos objetivos de um curso que se propõe interdisciplinar.

Antes de passar aos casos, e para situar nosso debate, começamos de uma questão simples, posta a partir da perspectiva de quem está responsável, dentro da estrutura do curso, pela área de direito. O que o direito tem a contribuir nessa formação ampla e interdisciplinar? Mais especificamente: o que só ele tem a contribuir para um profissional que vai trabalhar cotidianamente com políticas públicas?

Vamos iniciar pelo óbvio: a área de direito está em posição privilegiada para discutir - e desvelar em toda a sua complexidade - o que significa afirmar que vivemos em um Estado de Direito. Ou seja: que as ações dos agentes públicos estão limitadas e constrangidas pelos objetivos e competências estabelecidas previamente na Constituição e nas leis.

Em segundo lugar, o Estado se expressa majoritariamente por meio de normas jurídicas. Qualquer política ou programa que se queira implementar será provavelmente formalizado por meio de um instrumento jurídico. Só esses dois elementos deveriam ser suficientes para justificar o interesse em uma formação jurídica sólida para os alunos da do "campo de públicas".

Além disso, é nos instrumentos jurídicos que estão definidos, por exemplo, quais são os objetivos da política pública; quem serão os agentes; o desenho institucional para a realização da ação; qual o orçamento disponível; qual a forma de acompanhamento e avaliação. Se o Estado se expressa por meio da linguagem jurídica, isso não é diferente com as políticas públicas. A formulação de políticas públicas se dá em linguagem jurídica e recorrendo a instrumentos jurídicos. Essa dimensão prática, de instrumento para a ação concreta - e não meramente de análise sobre a realidade - garante aos professores de direito uma responsabilidade própria na formação de gestores públicos.

Aprender a manejar esses instrumentos; entender as imposições e limitações dos objetivos constitucionais e legais; aprender a discutir as diferentes interpretações dos textos normativos (e a saber que, na maior parte dos casos, não existe uma interpretação única), o desenvolvimento de todas essas habilidades confere ao direito uma relevância própria no estudo das políticas públicas.

Com essa análise preliminar, até agora, queremos salientar: a trajetória educacional do aluno do "campo de públicas" passa, necessariamente, por uma formação consistente na área de direito. Formação essa capaz de exibir com clareza os princípios fundamentais que organizam e estruturam o Direito Público, bem como de transmitir, a partir daí, algumas importantes técnicas de manejo do direito, que permitam ao aluno compreender a linguagem jurídica e utilizar-se de instrumentos jurídicos. Esse é um capital intelectual e prático, sem dúvida, indispensável aos pesquisadores e profissionais da área.

Mas essa formação consistente dentro da área de direito deve manter, como observamos, contato constante com áreas afins. De imediato, qual a dificuldade que 
surge dessa interação? Para indicar o núcleo do problema, vamos utilizar o conceito de "comunidade epistêmica". De fato, as áreas disciplinares que compõem o curso de políticas públicas têm, cada uma, sua própria comunidade epistêmica. Uma comunidade epistêmica caracteriza-se pelo fato de que seus membros compartilham, em maior ou menor medida: a) uma linguagem comum, dotada de certos conceitos que se supõem aptos a descrever os objetos de estudo do campo, mas que, bem considerados, estão também construindo esses objetos de estudo; $b$ ) uma avaliação comum acerca de quais são os problemas relevantes a serem resolvidos com relação a esses objetos; c) tendência a uniformizar certas crenças básicas, pré-teóricas, que permitem estruturar o campo de estudos; d) uma visão compartilhada a respeito de quais são os métodos válidos, aceitáveis, para a abordagem e resolução dos problemas da disciplina ${ }^{5}$.

Cada uma das grandes áreas que compõem o curso é ministrada por professores que, em sua origem, participavam do diálogo acadêmico em suas próprias comunidades epistêmicas. Isso significa dizer que os professores - antes de integrarem o corpo docente da graduação em políticas públicas - compartilhavam com os seus colegas disciplinares valores, visões de mundo, temas relevantes de pesquisa, critérios e metodologias para a construção e validação do conhecimento científico, práticas e formas de escrita acadêmica.

O nosso problema, agora, pode ser revelado sob uma nova forma: o desafio dos professores do campo de públicas reside, em certa medida, na necessidade de se afastarem de suas comunidades de origem para forjar uma comunidade epistêmica própria, interdisciplinar. Eis por que, na próxima seção, abordaremos justamente esse problema, a partir, como anunciado, do exame de casos concretos. Buscaremos mostrar como a abordagem interdisciplinar, ao afastar o professor de sua

\footnotetext{
${ }^{5}$ Buscando aplicar a noção de "comunidade epistêmica" à nossa área de interesse, Haas (1992, p. 03) escreve o seguinte: "The epistemic community is a network of professionals sharing a common worldview. This worldview involves beliefs about how causal relationships unfold in a given area; it also includes agreed methods for assessing these relationships, and normative beliefs about the policy implications. Ou ainda: "Although an epistemic community may consist of professionals from a variety of disciplines and backgrounds, they have (1) a shared set of normative and principled beliefs, which provide a value-based rationale for the social action of community members; (2) shared causal beliefs, which are derived from their analysis of practices leading or contributing to a central set of problems in their domain and which then serve as the basis for elucidating the multiple linkages between possible policy actions and desired outcomes; (3) shared notions of validity- that is, intersubjective, internally defined criteria for weighing and validating knowledge in the domain of their expertise; and (4) a common policy enterprise-that is, a set of common practices associated with a set of problems to which their professional competence is directed, presumably out of the conviction that human welfare will be enhanced as a consequence." (HAAS, 1992, p. 03). Já Zito (2001, p. 588) observa que: "Within this shared knowledge are common causal models, jargon and policy preferences. The epistemic community should persuade EU actors to conform to its consensual (i.e. intersubjectively constructed) ideas without recourse to more material forms of power."
} 
comunidade epistêmica original, pode enriquecer a prática docente, bem como o próprio debate acadêmico.

\section{O DESAFIO DA INTERDISCIPLINARIDADE EM TRÊS SITUAÇÕES CONCRETAS: A NECESSIDADE DE AFINAR A LINGUAGEM E OS CONCEITOS}

Discutimos a seguir três casos concretos que ilustram os desafios e possibilidades de trocas entre as comunidades epistêmicas do campo de públicas. Nosso foco recairá, sobretudo, no uso da linguagem e dos conceitos.

A primeira situação que merece ser relatada é a de uma potencial orientanda de iniciação científica que apresenta sua ideia inicial de projeto de pesquisa. Quer estudar o quanto há uma limitação da cidadania no Brasil, o quanto há indícios de retrocessos. Segundo ela "o Brasil é tão desigual, há tantas pessoas com tantas privações, que elas não conseguem sequer lutar por seus direitos...". Sua motivação, o que despertou o desejo de realizar a pesquisa, foi o conceito de cidadania descrito no texto clássico de Thomas Marshall (1967), que ela leu em uma aula de ciência política. Nele, é proposta uma relação entre classe social e possibilidade de realização da cidadania.

Além do debate teórico, porém, a estudante pretende fazer uma análise da atual conjuntura do Brasil. Como encaminhar as indagações dessa aluna, até ao ponto em que possam se tornar um projeto de iniciação científica?

Para encontrar um objeto concreto para sua pesquisa, a estratégia foi esta: sugerir que ela partisse do conceito de Marshall, mas caminhasse para outra comunidade epistêmica, não mais a da Ciência Política, mas sim a comunidade epistêmica dos direitos humanos. Quando ela afirma "cidadania limitada por condições econômicas e classe social", a orientadora escuta "violações a direitos fundamentais e direitos humanos", "interdependência entre direitos humanos", além de "proibição de retrocesso".

$\mathrm{O}$ tema de pesquisa transformou-se. O conceito de cidadania proposto por Marshall não desaparece, pelo contrário: devidamente investigado, deverá servir como mola da indagação proposta. Contudo, ele é transposto para outra esfera de preocupações. Esse processo de tradução conceitual não tem nada de trivial: $o$ conceito de cidadania, visto sob o viés jurídico do direito, e mais especificamente dos direitos humanos, ganha certa efetividade positiva e histórica. Com essa nova "roupagem", pode ser mais facilmente pensado em suas implicações para o Brasil do século XXI. Aquilo que está contido, como teoria, na crítica de Marshall, pode ser agora exibido, esmiuçado, avaliado segundo padrões mais facilmente acessíveis, extraídos de outro campo do saber.

A segunda situação foi extraída da sala de aula, durante o curso de Direito Constitucional. Discutia-se o caso judicial em que a Philip Morris S.A., indústria do tabaco, foi impedida de comercializar maços de cigarro com 14 unidades (GRAU, 
1988). A partir desse caso, buscou-se iluminar a tensão existente entre dois valores importantes para nossa ordem constitucional: livre iniciativa, por um lado, e direito à saúde, por outro.

Essa é uma estratégia que consideramos importante para a formação dos alunos: exibir os diversos temas do direito, não apenas em sua simplicidade e organização conceitual interna, mas frente à complexidade do real. Parte-se da concepção de que o direito é uma "prática social discursiva". O texto normativo é a moldura, que comporta inúmeras interpretações conflitantes. $\mathrm{O}$ debate sobre as possíveis interpretações compõe as reflexões sobre o texto na comunidade epistêmica do direito e, por fim, o próprio desenho institucional forjado normativamente define qual é ou quais são os órgãos competentes para dizer qual deve ser a interpretação a ser aplicada no caso concreto.

Temos aqui dois momentos necessários a qualquer estudo nessa área, dos quais um é, frequentemente, deixado de lado em benefício do outro. Vale a pena olhar com um pouco mais de atenção o que se passa, para verificar, também quanto a esse ponto, o valor da abordagem interdisciplinar, tal como a compreendemos.

Tanto do ponto de vista teórico quanto didático, o momento de abstração conceitual é indispensável na estruturação - e consequentemente na exposição - de qualquer campo do saber. Abstrair, etimologicamente, é retirar. Na organização abstrata de uma disciplina, o que foi retirado? Retirou-se, justamente, a aspereza do real, a complexidade do real, em prol de uma organização segundo esquemas inteligíveis. Eis aí, aliás, a essência da própria atividade discursiva, estruturada em conceitos. Ao aluno, evidentemente, precisa ser franqueado o caminho dessa abstração. Ele precisa conhecer teoria do direito constitucional, direito constitucional positivo, história constitucional brasileira etc.

No entanto, é igualmente importante que o real, com suas complexidades e asperezas, esteja igualmente presente na sua formação. Daí surge a estratégia de lidar com casos concretos, como aquele que estamos agora descrevendo. Usamos o caso da Philip Morris, selecionado de uma ampla gama de casos possíveis, todos compartilhando uma mesma característica: a exibição de um conflito socialmente relevante, a ser decidido por meio de recurso ao Poder Judiciário, no qual se opõem valores importantes da ordem constitucional. A realidade, aqui, resiste à esquematização inicial que o direito fora capaz de lhe oferecer. Essa é uma situação inevitável, e desejamos mostrar aos estudantes que, longe de ser exceção, ela é constitutiva do universo jurídico.

Mas onde entra, aqui, a abordagem interdisciplinar? Em certo sentido, a abordagem interdisciplinar corresponde justamente à reintrodução da complexidade. Ela encontra seu caminho, e mostra sua relevância, precisamente nesse momento em que o esquema jurídico, ao embater-se com a realidade, vai exibindo seus limites. É preciso interpretar a norma constitucional, é preciso harmonizar os valores constitucionalmente protegidos. Como fazê-lo? 
A partir da teoria do constitucionalista Robert Alexy, discutimos com os alunos o critério de adequação, como forma de ponderar entre valores constitucionais que se opõem, em determinado caso concreto. Esse critério pode ser considerado cumprido quando um determinado objetivo é fomentado:

Adequado, então, não é somente o meio com cuja utilização um objetivo é alcançado, mas também o meio com cuja utilização a realização de um objetivo é fomentada, promovida, ainda que o objetivo não seja completamente realizado. (...) Dessa forma, uma medida somente pode ser considerada inadequada se sua utilização não contribuir em nada para fomentar a realização do objetivo pretendido. (SILVA, 2002, p. 36)

Em meio à discussão do caso concreto, mais especificamente no debate sobre a questão "a proibição da venda de maços de cigarro com 14 cigarros promove ou fomenta o direito à saúde?", uma das estudantes presentes na aula objetou: "é possível dizer que uma proibição desse tipo fomenta ou promove a saúde? Ela só não está impedindo que uma situação pior venha a existir? Promover a saúde é construir hospital, unidade básica de saúde, fazer política pública...".

O contato com os alunos, que vão se servindo da formação interdisciplinar proporcionada pelo curso de gestão de Políticas Públicas, traz um ponto de vista novo à questão. A professora, oriunda de certa comunidade epistêmica na qual essa questão dificilmente teria surgido, precisa estar aberta, e refletir novamente a respeito do assunto. É necessário incorporar essa dúvida como parte integrante, e bastante relevante, da reflexão a respeito do caso tratado.

A percepção inicial é esta: para estudantes de políticas públicas, que têm como repertório também as referências bibliográficas da administração pública e da ciência política, os verbos "fomentar" e "promover" estão inapelavelmente associados a ações positivas do poder público. Na literatura do Direito Constitucional, porém, não é assim. A partir dessa dissonância vocabular, que precisa ser explicitada e discutida, um novo problema emergiu.

Qual a relação entre as ações positivas da administração pública e a atividade jurisdicional do Estado, particularmente em âmbito constitucional? Abrese aqui, de forma natural e surpreendentemente fecunda, dentro de um curso com perfil interdisciplinar, uma ponte privilegiada para discutir com os alunos, e para pensar, um tema central, hoje, tanto para o próprio direito como para a ciência política: o tema da judicialização das políticas públicas.

Finalmente, a terceira situação concreta diz respeito, não mais ao campo didático, em sala de aula, mas ao campo da pesquisa. Em um grupo interdisciplinar de estudos denominado "Neoliberalismo, subjetivação e resistências", atualmente vinculado ao Instituto de Estudos Avançados da USP, nos debruçamos sobre a obra "Comum" dos autores franceses Pierre Dardot e Christian Laval (filósofo e 
sociólogo, respectivamente). Suas análises passam por conceitos como "instituição", "direito", "costume". Exemplarmente, selecionamos os seguintes trechos:

O que nos parece é que a produção de um direito do comum não pode ser pensada apenas nos termos do 'direito consuetudinário'. Não que o costume não possa produzir direito; o que acontece é que essa produção é fundamentalmente da ordem da transmissão inconsciente de regras muito antigas. Como vimos, essa transmissão é confirmadora e recondutora em sua essência, mesmo quando produz modificações de longo prazo. Por isso, é incapaz de instituir por si própria o inapropriável, visto que esse ato instituinte tem de ser consciente: na verdade, trata-se de voltar o direito do uso contra a propriedade, seja ela privada ou estatal.

(...)

Consequentemente, a questão preliminar é saber por qual prática podemos inventar regras de direito capazes de se tornar costumes no longo prazo. (...) Em compensação, se ninguém, seja indivíduo ou coletivo, consegue instituir um costume, as pessoas podem produzir regras de direito por meio de sua prática coletiva, não só independentemente de leis existentes, mas, se for o caso, contra elas. Não é possível dizer de antemão a transformação dessa prática em costume, mas pode-se agir para reativar continuamente o poder que presidiu à instituição dessas regras, o que, sem dúvida, é a melhor forma de 'transformar' essas regras em costumes. Pois, embora seja verdade que não se decreta um costume, é possível decidir a instituição de regras capazes de se tornarem costumes pela força da prática. Encontramos aqui o terrível problema da instituição entendida como ato. (DARDOT, 2017, p. 429-430)

(...)

A maneira mais direta de mostrar isso é enunciar de vez nossa tese: a práxis emancipadora é práxis instituinte ou atividade consciente de instituição. O que entendemos exatamente por atividade de instituição ou atividade instituinte? Começaremos fazendo duas delimitações negativas: instituir, que consiste acima de tudo em estabelecer regras de direito, não é nem criar ex nihilo essas regras nem oficializar ou consagrar post factum regras que já existiam, mas não eram ainda reconhecidas como regras de direito. (DARDOT, 2017, p. 466)

Os trechos acima mostram que os autores mobilizam conceitos caros para a comunidade epistêmica do direito. Antes dos conceitos, os autores parecem romper com uma ideia bastante cara de que o que diferencia o direito propriamente dito de 
outras normatividades é o fato de que as normas jurídicas são garantidas, em última instância, pelas forças coercitivas do Estado. Estado esse que, por sua vez, detém o monopólio da violência legítima.

Além disso, têm suas próprias definições de "instituição", "direito", "costume", "regra", "lei". A obra tem uma lógica interna. Mas as definições que os autores apresentam para esses conceitos se distanciam dos conceitos mais ou menos estabilizados na comunidade epistêmica do direito. É ao mesmo tempo instigante e desconfortável lidar com esse novo repertório. Ao mesmo tempo que é um desafio explicar o desconforto para os outros membros do grupo, que não são do direito.

Os três casos relatados acima explicitam um constante desafio para aqueles que estão em cursos interdisciplinares: o desafio do ajuste conceitual. Muitas vezes as palavras utilizadas por diferentes comunidades epistêmicas são semelhantes ou iguais. Seus significados são diferentes em diferentes contextos. Para que trocas produtivas se realizem, é preciso ajustar a linguagem. Garantir que todos os participantes do debate acadêmicos estejam "falando a mesma língua" nos debates. Isso exige paciência e repactuação conceitual constante se o objetivo é entrar em um processo de troca entre os campos de conhecimento do curso.

\section{A EXPERIÊNCIA da Escola de ARTES, CiÊnCIAS E Humanidades da USP}

Passamos agora a uma segunda ordem de considerações, pertinente à organização institucional de um curso concreto: o de Gestão de Políticas Públicas da Escola de Artes, Ciências e Humanidades da USP. Esta segunda parte do artigo tem por objetivo, assim, identificar as dificuldades da interdisciplinaridade não em questões acadêmicas concretas mas no próprio desenho institucional do curso de graduação.

O curso de Gestão de Gestão de Políticas Públicas da USP Leste iniciou suas atividades em 2005. Desde então, todos os inícios de ano, 120 calouros iniciam sua formação, sendo 60 no período matutino e 60 no período noturno. Em 2008, uma primeira turma de estudantes foi formada. Em 2010, já levando em conta as devolutivas desses estudantes recém-formados, uma nova estrutura curricular foi aprovada nas instâncias colegiadas da Escola. Ajustes no conteúdo e na carga horária das disciplinas foram feitos, bem como adequações na sequência lógica das disciplinas. Em 2011, essa nova organização curricular começou a valer.

Em 2016, por sua vez, mais uma vez o Projeto Político Pedagógico (PPP) do curso de Gestão de Políticas Públicas e sua estrutura curricular foram alterados. E, agora, em 2019, uma nova rodada de reflexões sobre as disciplinas e suas características está em processo. Essas datas: 2011, 2016 e, possivelmente, 2020, mostram um curso novo e em um permanente esforço de aperfeiçoamento institucional. Aprofundamento do caráter interdisciplinar da formação básica e 
superação da dicotomia entre técnica e política estavam entre os objetivos explícitos na última alteração do PPP (SÃO PAULO, 2016).

O objetivo geral do curso é, antes de tudo, a formação de um estudante crítico, que saia da graduação com uma visão global das diferentes áreas de conhecimento que abrangem o dia a dia da administração pública. No PPP de 2016, o objetivo geral é formulado da seguinte forma:

O objetivo geral do curso de graduação em Gestão de Políticas Públicas da $\mathrm{EACH} / \mathrm{USP}$ centra-se na formação de recursos humanos em nível superior capazes de atuarem com competência técnica junto aos diversos entes (estatais e não estatais) da sociedade que atuam diretamente nas várias etapas das Políticas Públicas - Formulação, Implementação e Avaliação - e/ou que se utilizam de processos de Gestão Pública; além de serem capazes de empreenderem análises sobre a realidade política, econômica e social na qual estão inseridos, e com a qual as organizações em que atuam interagem. (SÃO PAULO, 2016)

Já entre os objetivos específicos, lê-se:

I - Formação humanística e interdisciplinar acentuada, concernente com as diretrizes da EACH/USP, entre as quais tal formação é um dos pilares do seu projeto político pedagógico;

II- Formação básica e introdutória em áreas do conhecimento fundamentais para a atuação profissional do Gestor de Políticas Públicas; além de colaborar para a consolidação de sua capacidade de análise crítica da realidade social. São estas áreas do conhecimento a Administração (com ênfase em Administração Pública), as Ciências Sociais (com ênfase na Ciência Política), a Economia e o Direito;

Note-se que, muito embora se espere dos alunos que participem de uma formação interdisciplinar, dos professores espera-se que apresentem de forma básica e introdutória as suas próprias áreas de conhecimento. Além desses dois objetivos específicos, nada mais é dito sobre as áreas que compõem a formação do curso de graduação em Gestão de Políticas Públicas. Ao menos explicitamente, a interdisciplinaridade fica muito mais localizada no resultado que se espera dos estudantes do que de um esforço dos professores em proporcioná-lo.

Embora seja uma prática das bancas de concurso realizadas no curso, a interdisciplinaridade também não é requisito explícito - ao menos não no PPP - para os professores que vão ser contratados pela Escola. A preocupação com a formação 
interdisciplinar dos docentes que vão participar do projeto do curso fica, assim, muito mais como uma característica prática do que normativa do curso. Atualmente, o curso de Gestão de Políticas Públicas tem 26 professores efetivos.

\section{Uma especificidade da EACH/USP: a existência do Ciclo Básico}

O ciclo básico é uma inovação em termos de ensino interdisciplinar, criado pela $\mathrm{EACH} / \mathrm{USP}$, como sendo um "eixo formativo comum a todos os cursos da EACH, independentemente da área". ${ }^{6}$ Ao cursarem disciplinas introdutórias, de caráter humanista com o intuito de contribuir para a sua formação cidadã, os estudantes dos onze diferentes cursos de graduação da $\mathrm{EACH}$, quais sejam, Biotecnologia, Ciências da natureza, Educação física e saúde, Gerontologia, Gestão ambiental, Gestão de políticas públicas, Lazer e turismo, Marketing, Obstetrícia, Sistemas de informação, Têxtil e moda, se formam para enfrentarem os desafios de suas áreas específicas.

De acordo com a descrição do ciclo básico,

Essa proposta acadêmica enfatiza a heterogeneidade de saberes docentes e discentes e as possibilidades da análise ampliada do contexto social a partir da composição de múltiplos olhares disciplinares, com vistas à construção de um ambiente acadêmico dinâmico, participativo e constantemente oxigenado pelo debate e reflexão coletivos. Desse modo, o projeto pedagógico da EACH, destacando os princípios do Ciclo Básico, assume o compromisso de oferecer uma formação acadêmica e profissional sólida aos/às seus/suas alunos/as, estimulando o estreitamento das relações entre comunidades e universidade, fomentando uma relação de ensino-aprendizagem propositiva e a produção de conhecimento de excelência, que caracteriza a tradição da Universidade de São Paulo.7 (grifos no original)

O objetivo maior dessa atividade interdisciplinar é preparar nossos alunos para enfrentar os desafios de seus campos profissionais a partir de uma visão mais ampla e crítica da sociedade, da cultura e da ciência, de forma a estarem mais bem preparados para viver no mundo contemporâneo. Ainda de acordo com a descrição do ciclo, são três suas áreas centrais.

A primeira é introdutória, com o objetivo de levar os estudantes a compreenderem as ideias gerais do curso. A segunda área é a da formação geral,

6 A descrição do ciclo básico pode ser encontrada no seguinte endereço:<http://www5.each.usp.br/ciclo-basico/>. Acesso em 29 maio 2018.

7 A descrição do ciclo básico pode ser encontrada no seguinte endereço: $<$ http://www5.each.usp.br/ciclo-basico/>. Acesso em 29 maio 2018. 
que aponte aos alunos a complexidade dos fenômenos naturais, culturais e sociais, a partir de uma integração planejada das áreas de ciências naturais, de humanidades e das artes, fundamentadas em bases filosóficas do conhecimento científico, abrangendo, inclusive, a noção de direitos humanos e cidadania.

Uma terceira área, denominada científica, busca estimular as atividades de resolução de problemas, cujo intuito é iniciar os alunos em projetos de iniciação científica e iniciar os alunos no estudo de propostas de pesquisas.

Por ser um curso geral, atribuído, desde o processo de seleção de ingresso, a docentes de diferentes áreas de conhecimento - no caso, os dois subscritores deste artigo, por coincidência -, há diretrizes gerais para a formação dos programas que levam essa heterogeneidade em consideração. Do contrário, seria impossível imaginar um programa único com tantas vertentes interdisciplinares sobre um curso tão genérico.

Geralmente oferecidas nos primeiros semestres dos diferentes cursos, as disciplinas "Sociedade, Multiculturalismo e Direitos" e a disciplina "Ciências da Vida e Ciências da Terra" podem ganhar ainda diferentes ênfases, a critério dos docentes designados para ministrar as disciplinas, a saber:

\begin{tabular}{|l|l|}
\hline $\begin{array}{l}\text { Sociedade, Multiculturalismo e Direitos } \\
\text { (SMD) }\end{array}$ & $\begin{array}{l}\text { Ciências da Vida e Ciências da Terra (CV } \\
\text { e CT) }\end{array}$ \\
\hline $\begin{array}{l}\text { • }{ }^{*} \text { Cultura Digital; } \\
\text { - }{ }^{*} \text { Direitos Humanos e Multiculturalismo } \\
\text { - }{ }^{*} \text { Estado e Sociedade. }\end{array}$ & $\begin{array}{l}\text { - } \text { Ciência, Cultura e Sociedade; } \\
\text { - } \text { "Ciências da Vida e da Terra; } \\
\text { - } \text { *Ciências do Universo. }\end{array}$ \\
\hline
\end{tabular}

No segundo semestre, as disciplinas e suas respectivas ênfases podem ser assim descritas:

\begin{tabular}{|c|c|c|}
\hline $\begin{array}{lr}\text { Campo } & \text { Psicologia, } \\
\text { Educação e e } & \text { Temas } \\
\text { Contemporâneos (PET) }\end{array}$ & $\begin{array}{l}\text { Campo Sociedade, } \\
\text { Meio Ambiente e } \\
\text { Cidadania (SMC) }\end{array}$ & $\begin{array}{l}\text { Campo Arte, Literatura } \\
\text { Cultura (ALC) }\end{array}$ \\
\hline $\begin{array}{l}\text {-*Uma Abordagem Crítica; } \\
\text { •*Uma Visão Psicanalítica; } \\
\text { •*Processos Sociais de } \\
\text { Formação dos Indivíduos. }\end{array}$ & $\begin{array}{l}\text { - } \text { *Sociedade, Meio } \\
\text { Ambiente } \\
\text { Cidadania; } \\
\text { •Desenvolvimento e } \\
\text { Meio Ambiente. }\end{array}$ & $\begin{array}{l}\text { •*Arte Contemporânea } \\
\text { •*Literatura Contemporânea } \\
\text { - Fantasia e Ficção Científica na } \\
\text { Cultura Pop; } \\
\text { •*Arte, Literatura e Cultura no } \\
\text { Brasil. }\end{array}$ \\
\hline
\end{tabular}

Os docentes autores deste texto são responsáveis por ministrar, a critério da coordenação de curso, a disciplina Sociedade, Multiculturalismo e Direitos no primeiro semestre. A ênfase pode variar entre Direitos Humanos e Multiculturalismo ou Estado e Sociedade. Para tanto, direcionam seus cursos para uma explicação da existência do fenômeno estatal a partir dos arranjos sociais o que implica, de certa forma, na abordagem de elementos da Teoria Geral do Estado. 
Contudo, como não ministram essas disciplinas especificamente para os alunos do Curso de Gestão em Políticas Públicas, posteriormente, terão de retomar esses conceitos com os alunos do curso, na matéria Direito Constitucional. Há ainda uma abordagem sobre o conceito de multiculturalismo que, até o contato com o curso de SMD, era um conceito estranho aos docentes formados no campo jurídico.

Ainda no Ciclo Básico, duas disciplinas denominadas "Resolução de Problemas I e II" (Problem Based Learning - PBL) são oferecidas. Elas partem de um compromisso com as metodologias ativas de ensino-aprendizagem. Os estudantes são estimulados a formular coletivamente (em grupos de quatro a cinco pessoas) projetos de pesquisa interdisciplinares e desenvolverem a pesquisa ao longo do semestre. Essa estratégia - tutorada por professores de diferentes áreas - de fato prepara os estudantes para futuros projetos de pesquisa, introduzem o método e a escrita científica já no primeiro ano e favorecem a interdisciplinaridade. Processo semelhante ocorre nos trabalhos de conclusão de curso (TCCs).

\section{O curso na prática}

A impressão que temos ao deparar com os alunos de primeiro ano é a de que, ao contrário dos cursos tradicionais, não há qualquer predileção por uma área ou um campo de conhecimento dos vários que irão compor a sua graduação no momento inicial. É evidente que o interesse surge de forma mais específica à medida que o aluno se envolve, ao longo dos semestres, com diferentes matérias e áreas de conhecimento.

Muitas vezes o que enriquece o debate no curso é a abordagem de um mesmo tema e, muitas vezes, os mesmos autores, sob a perspectiva de diferentes professores, a partir da perspectiva de suas diferentes comunidades epistêmicas de conhecimento. É comum os alunos tomarem contato com os pensadores da teoria contratualista, na perspectiva dos professores da ciência política, por exemplo. Retomarão esses conceitos, da perspectiva dos professores da área jurídica e da Teoria Geral do Estado, na disciplina Direito Constitucional, ministrada no terceiro período.

Isso permite que, a partir de diferentes leituras dos mesmos conceitos e autores, surja um diálogo entre as áreas - ou elas mostrem as especificidades dos diferentes olhares. Aqui cabe também uma ilustração. Um cientista político tem, por exemplo, um olhar mais comprometido com a análise e crítica dos diferentes desenhos institucionais das políticas públicas. Um professor de direito está preocupado com a efetiva tomada de decisão e seus critérios.

A dogmática jurídica leva a um ponto final - seja ele material, seja ele de competência - porque a reflexão infinita leva à paralisia e não à ação e decisão. Isso tem impacto na forma como as diferentes áreas se aproximam do conhecimento, por quais métodos querem conhecer a realidade das políticas públicas. E por isso é 
mais fácil para quem parte da abordagem "Direito e Políticas Públicas"8 afirmar que seu próprio objeto de estudo - o direito - pode ser visto como um "instrumento". Um cientista político nunca diria que a Ciência Política é instrumento para nada. Muito menos para a formulação, implementação e avaliação de políticas públicas.

Da perspectiva dos alunos, acreditamos que essa formação mais generalista, porém com diferentes abordagens sobre temas e às vezes autores iguais, permite a aquisição do conhecimento de forma mais ampla e, ao mesmo tempo, mais diversificada da perspectiva do foco e abordagem. Vai-se além de ensinar conceitos gerais. Trata-se de fato de uma formação interdisciplinar, mesmo quando o mesmo autor permeia os textos acadêmicos de leitura obrigatória ao longo dos semestres.

Da perspectiva dos docentes, por sua vez, é realmente enriquecedor participar dos primeiros contatos com os estudantes ao tratar de temas e autores já trabalhados por eles em diferentes semestres. Certamente nos sentimos diante de um processo de aprendizagem recíproco, em que as diferentes visões - estudante e professor - sobre um mesmo autor se conciliam, em um processo interativo bastante proveitoso. Não é incomum a divergência de entendimento sobre determinados conceitos, apreendidos sob diferentes perspectivas, o que torna a discussão em sala rica.

Neste ponto, aliás, cabe talvez um parênteses. É frequente o incômodo de alguns professores quanto à falta de espaços institucionais - como reuniões pedagógicas em que efetivamente o programa ou o Projeto Político Pedagógico do curso sejam discutidos. Sente-se falta de momentos em que os professores troquem programas, bibliografias, ideias sobre prioridades nas próprias áreas disciplinares ou em áreas próximas. Em reuniões da coordenação de curso - que muitas vezes se limitam às discussões cotidianas, práticas, como distribuição da carga horária entre os professores ou decisões sobre afastamentos - é frequentemente notada a ausência de discussões pedagógicas, até para promover a maior interação entre as comunidades epistêmicas, entre as diferentes disciplinas e áreas do curso.

De forma surpreendente, essa integração acontece muito frequentemente em sala de aula, por meio dos estudantes. Eles relatam e trazem para o debate temas e textos que viram e discutiram em outras disciplinas. Assim, por meio dos estudantes, a interdisciplinaridade se realiza. E, por inadequada que seja a forma, a afinação pedagógica do curso também.

Quanto ao direito e seu local no desenho institucional do curso, interessante notar que as matérias jurídicas obrigatórias da grade do curso de graduação em Gestão de Políticas Públicas geralmente são oferecidas em semestres do meio do

\footnotetext{
8 Aqui nos filiamos explicitamente à opção conceitual da professora Maria Paula Dallari Bucci: Direito e Políticas Públicas como uma abordagem do direito, abordagem que não quer se fechar como um campo. BUCCI, Maria Paula Dalari. (2019). Método e aplicações da abordagem Direito e Políticas Públicas. Revista de Estudos Institucionais (REI): Neste Dossiê.
} 
curso. A primeira delas é Direito Constitucional, no terceiro período. Direito Administrativo, no quarto, Direito Financeiro, no quinto período e Poder Judiciário e Políticas Públicas, apenas no oitavo período ideal.

Com isso, nós, docentes, ministramos as disciplinas do direito após os alunos de graduação já terem cursado, por exemplo, Introdução à Sociologia, Introdução ao Estudo de Políticas Públicas, Introdução ao Estudo da Política, Introdução à Economia, Introdução à Administração, dentre outras.

Se, em um curso tradicional de direito, os alunos que iniciam Direito Constitucional tem como matérias anteriores Introdução ao Estudo do Direito, Teoria Geral do Direito Privado, Fundamentos de Direito Público, História do Direito, Introdução à Sociologia e Teoria Geral do Estado, ou seja, matérias em sua grande maioria típicas do campo do direito, os alunos de gestão pública iniciam o estudo do Direito Constitucional sem ter, antes, qualquer fundamento jurídico. Outras áreas, comparativamente, têm suas matérias introdutórias privilegiadas.

Isso traz um desafio muito grande para o docente cuja formação é a do direito. É preciso compatibilizar, em um curso de Direito Constitucional, tanto a resposta à perguntas fundamentais como "o que é direito?" e "por que o Estado e direito estão tão ligados no Estado Moderno?" (e portanto, falar de temas típicos de disciplinas como Introdução ao Estudo do Direito e Teoria geral do Estado), como também apresentar aos futuros gestores públicos a dogmática da Constituição e, ao mesmo texto, uma visão geral sobre hermenêutica constitucional.

Some-se a esse fato ainda um agravante: enquanto os cursos tradicionais de direito dedicam dois semestres para o curso de Direito Constitucional, no curso de Gestão de Políticas Públicas da EACH a matéria está prevista para ser ministrada em apenas um semestre. É realmente desafiador apresentar aos alunos conceitos e explicar a aplicabilidade do tema no que será o dia a dia de suas atividades profissionais em tão curto espaço pedagógico. Direito Financeiro e Direito Administrativo apresentam desafios disciplinares semelhantes.

\section{A judicialização da política, o processo legislativo e a importância do estudo do campo jurídico nas políticas públicas}

Uma coisa é certa: no Curso de Gestão de Políticas Públicas os professores de direito são minoria. De 26 docentes efetivos, apenas cinco deles têm a formação jurídica. E apenas quatro estão designados para ministrar as matérias relacionadas ao direito no Curso.

Os professores da área jurídica às vezes podem ser considerados por seus colegas de curso, majoritariamente do campo da ciência política, como os que engessam o desenvolvimento do raciocínio na busca de soluções acadêmicas a partir análise racional da norma, que limita a ação, que estabelece regras.

Algumas vezes presenciamos a crítica de diferentes docentes acerca de uma explicação jurídica ou uma eventual alusão à interpretação de liberdades por meio 
do texto constitucional, inclusive. Trocando em miúdos, é como se os professores da área jurídica quisessem dar fim às discussões utilizando-se, em última instância, do argumento de autoridade da interpretação do texto constitucional dada pelos ministros do STF, por exemplo. Isso soa, de alguma maneira, como uma limitação do pensamento crítico dos cientistas políticos.

Retoma-se, aqui a concepção já explicitada acima, de que o direito é uma "prática social discursiva". O texto normativo é a moldura, que comporta inúmeras interpretações conflitantes (debate doutrinário sobre a interpretação do texto legal). O debate sobre as possíveis interpretações compõe as reflexões sobre o texto na comunidade epistêmica do direito e, por fim, o próprio desenho institucional forjado normativamente define qual é ou quais são os órgãos competentes para dizer qual deve ser a interpretação a ser aplicada no caso concreto.

O fato de reconhecermos que há órgãos, majoritariamente do Poder Judiciário, competentes para colocar um ponto final no debate doutrinário - ainda que seja um ponto final provisório, sempre sujeito à revisão posterior - não nos faz dogmáticos ou acríticos. Apenas indica que temos consciência de um mecanismo típico do direito para pôr fim a controvérsias interpretativas.

É interessante que a partir do crescimento do protagonismo do Supremo Tribunal Federal, em uma análise mais genérica, na cena política brasileira, e do Poder Judiciário de forma mais ampla, em debates que têm pautado a discussão nacional, como, por exemplo, o advento da prisão após a segunda instância, o interesse pelas demais áreas de conhecimento, nem que apenas como curiosidade, despertou.

Foi o STF que recentemente reconheceu constitucional a política de cotas ${ }^{9}$, decidiu sobre ensino religioso em instituições públicas ${ }^{10}$, dirimiu um importante conflito político no derradeiro processo eleitoral, ao proibir a invasão das universidades pela polícia a fim de tolher manifestações políticas ${ }^{11}$, além de tratar de inúmeras questões relacionadas ao processo eleitoral, anteriormente discutidas e votadas pelo parlamento e tão trabalhadas no campo da ciência política, como por exemplo a fidelidade partidária ${ }^{12}$, a forma de financiamento das campanhas eleitorais ${ }^{13}$, além de questões relacionadas aos costumes, que também despertam interesse das diferentes áreas de conhecimento, dentre as quais a união civil de pessoas do mesmo $\operatorname{sexo}^{14} \mathrm{e}$ a criminalização da homofobia ${ }^{15}$.

Some-se a isso o comportamento do Judiciário, em suas mais diferentes instâncias, acerca do julgamento da prisão em segunda instância e o impacto

\footnotetext{
9 Ação Declaratória de Constitucionalidade 41/DF.

${ }^{10}$ Ação Direta de Inconstitucionalidade 4.439/DF.

${ }^{11}$ Arguição de Descumprimento de Preceito Fundamental 548/DF.

${ }^{12}$ Mandado de Segurança 26.602/DF.

${ }^{13}$ Ação Direta de Inconstitucionalidade 4.650/DF.

${ }^{14}$ Arguição de Descumprimento de Preceito Fundamental 132/DF.

${ }^{15}$ Ação Direta de Inconstitucionalidade por Omissão 26/DF.
} 
político dessa decisão no cenário eleitoral brasileiro. Certamente este terceiro Poder, só muito recentemente elevado a objeto prioritário na comunidade epistêmica da Ciência Política, não tem passado despercebido, tampouco tem deixado de ser objeto de críticas por atores desses diferentes campos.

Isso provocou uma interação maior entre os docentes da Ciência política, Economia e Administração e os do Direito. Os pesquisadores das diferentes áreas vêm tentando aprender e compreender mais o Judiciário e os impactos de suas decisões na vida da sociedade nesse difícil momento de crise política do País, momento em que as instituições estão corriqueiramente colocadas à prova da vida política brasileira.

O mesmo fenômeno tem aproximado os diferentes campos epistêmicos no campo de públicas, no que concerne ao processo constitucional e regimental de formação das leis. A formalidade do processo legislativo, analisado na comunidade epistêmica da ciência política majoritariamente a partir da lógica do presidencialismo de coalizão, passou a ter uma maior importância a partir do acirramento da crise política que vem afligindo a sociedade brasileira nos últimos anos.

Se tomarmos como exemplos os últimos anos no Brasil, não são poucos os exemplos de desrespeito formal ao processo de formação das leis, adotados reiteradas vezes pelo Executivo, na tentativa de obter favorecimento às suas propostas políticas via processo legislativo. E é justamente o formalismo jurídico do processo legislativo que tem limitado esses rompantes, principalmente a partir da edição de medidas provisórias.

Os exemplos acima citados demonstram, de forma cabal, que nos momentos de crise política aguda, como essa que hoje vivenciamos, o próprio processo legislativo necessita ser observado a partir de um enfoque mais rígido e formalista, o que traz para o campo do direito as soluções para os impasses do processo legislativo e aproxima o enfoque jurídico daquele abordado pelas diferentes áreas epistêmicas que também estudam a arena jurídico-política do Poder Legislativo.

\section{REFLEX̃̃ES FINAIS}

O campo de formação em políticas públicas é marcado pela interdisciplinaridade. Isso significa dizer que uma graduação em gestão de políticas públicas espera formar uma pessoa capaz de transitar em diferentes áreas do conhecimento que, tradicionalmente, são apartadas uma das outras, participam de diferentes comunidades epistêmicas.

Curiosamente, ao analisarmos o caso concreto do curso de Gestão de Políticas Públicas da Escola de Artes, Ciências e Humanidades da USP, espera-se que o salto para a interdisciplinaridade seja dado pelos estudantes. Aos professores cabe ministrar de forma competente os fundamentos e disciplinas de suas próprias áreas disciplinares (com exceção daqueles professores que participam do ciclo básico). 
Estratégias para que a formação interdisciplinar se realize não têm espaços institucionais claros de elaboração. Elas acontecem pela integração que ocorre em espaços informais - conversas de corredor, café, almoços, a própria sala de aula na troca com os estudantes. Nas atividades regulares formais, espera-se que a professora ou o professor seja competente em sua área disciplinar, produza de forma competente para a sua própria comunidade epistêmica. A dinâmica fica um pouco mais complexa se este professor integrar uma pós-graduação interdisciplinar.

O que significaria, porém, ser um curso interdisciplinar? Deveria o campo de políticas públicas forjar uma nova comunidade epistêmica, com sua própria linguagem, seus próprios conceitos, problemas relevantes de pesquisa, métodos compartilhados? Esse seria o horizonte almejado? O direito, nesse contexto, seria dissolvido em suas especificidades na nova comunidade epistêmica? Ou ele guardaria ainda uma integridade e dignidade próprias? Essas parecem ser questões fundamentais, para as quais não pretendemos dar respostas definitivas.

Nessa primeira aproximação com o debate, nos parece que ensinar direito em um curso de gestão de políticas públicas significa viver cotidianamente a tensão entre a abertura do direito para outras áreas do conhecimento, outras comunidades epistêmicas - ciência política, sociologia, economia, administração pública - e a preservação de sua dignidade e integridade próprias, a preservação de características que tornam o conhecimento típico da comunidade epistêmica do direito valioso para um futuro gestor de políticas públicas.

Se o Estado de Direito e suas formas de ação são objeto de estudo de mais de uma área que compõe a formação do curso, é na comunidade epistêmica do direito em que as questões práticas e as decisões que devem ser tomadas para a observância ao princípio da legalidade estrita são investigadas. O direito está presente - porque oferece balizas e parâmetros - em todas as ações feitas em nome do Estado. E o estudo de como estes mecanismos de afirmação de competência e de limites da discricionariedade da ação se dão está na raiz dos estudos jurídicos presentes no curso de políticas públicas. Objetivos e competências estabelecidos previamente na Constituição e nas leis devem ser conhecidos e observados.

No Estado de Direito, o direito tem uma pretensão altiva: impedir o exercício arbitrário do poder, impedir que os agentes estatais se excedam. Nesse sentido, entender os mecanismos e linguagens contribui para que esse núcleo simbólico se realize na prática da burocracia estatal. Por outro lado, a compreensão de que o direito é uma prática social discursiva, permite aos estudantes perceber que, para além das decisões já tomadas pelos órgãos competentes, há muito da interpretação da moldura do texto normativo que está permanentemente em debate.

Ser capaz de navegar minimamente pela linguagem da comunidade epistêmica do direito e ser capaz de discutir também com os formados em cursos jurídicos parecem-nos importantes habilidades de um gestor de políticas públicas. O Estado de Direito fala linguagem jurídica. Ao formular um programa ou uma 
política, ao formalizar seus objetivos, ao realizar planejamento: uma vez tomada a decisão política, na grande maior parte das vezes ela se cristaliza em um documento normativo.

Assim, nosso papel no curso é fazer com que os estudantes sintam-se preparados a construir e interpretar textos jurídicos ou, no mínimo, a dialogar também nesta específica comunidade. Por outro lado, é preciso também estar aberto aos aportes das outras disciplinas, não ignorar todos os outros conhecimentos, referências, métodos das outras áreas do curso.

Para nós, professores de direito de um curso de gestão de políticas públicas, é comum a sensação de que os estudantes valorizam menos esse campo do saber preferindo, por exemplo, a ciência política. Já ouvimos, por exemplo, que enquanto os juristas estão preocupados com o dever ser normativo - que nunca se realiza plenamente na prática da política - os cientistas políticos, sim, olham para a complexidade do real e a descrevem. Os juristas ficam com um dever ser imaginário enquanto os cientistas políticos saberiam mais sobre como as coisas realmente são.

Ignora-se, nessa percepção, que consideramos injusta, um papel fundamental da prática discursiva "direito". Seu papel criativo. Ao formular como as coisas deveriam ser, deveriam se tornar, pode se estar cristalizando desejos políticos. A linguagem do direito é também a linguagem do futuro, é a linguagem da formulação do desejo de uma vida em sociedade mais justa, de uma vida em que políticas públicas sejam mais amplas e mais adequadamente construídas e formalizadas. Os agentes estatais estão e estarão - enquanto se quiser preservar a limitação contra a arbitrariedade do exercício do poder - limitados por essa linguagem jurídica que, em um processo contínuo, limita e formula novos objetivos para a ação estatal. Só aquilo que está formalizado em linguagem jurídica pode se realizar como ação estatal, como política pública.

Essa relação íntima entre limitação da ação dos agentes do Estado, por um lado, e potencial criativo, de estabelecer novos objetivos e novas competências, por outro - ambos ligados à linguagem do direito - é o que de mais precioso e valioso podemos compartilhar da lógica jurídica com os futuros gestores públicos. Obviamente, para que o instrumento seja bem utilizado, ele precisa se alimentar de reflexões e aportes de inúmeras outras áreas.

Ao direito, no curso interdisciplinar de gestão de políticas públicas, cabe vivenciar a tensão: manter a dignidade e a integridade própria de sua própria comunidade epistêmica e, ao mesmo tempo, se integrar em uma nova comunidade epistêmica das políticas públicas que, com a criação dos cursos de graduação e pósgraduação, paulatinamente vem sendo criada. Manter-se ligado à essas duas comunidades parece-nos o caminho mais acertado. Aos professores que são responsáveis pela área espera-se que acompanhem seu objeto. 


\section{REFERÊNCIAS}

BENEVIDES, Maria Vitoria de Mesquita. Cidadania e Democracia. Revista Lua Nova, n. 33, 1994.

BRUNET, Emiliano. Sobre a abordagem acadêmica de políticas públicas em um curso de graduação em direito: contribuição para um programa. REI - Revista de Estudos Institucionais, v. 5. n. 3, 2019.

BUCCI, Maria Paula Dallari. Fundamentos para uma teoria jurídica das políticas públicas. São Paulo: Saraiva, 2013.

BUCCI, Maria Paula Dallari. Método e aplicações da abordagem Direito e Políticas Públicas. REI - Revista de Estudos Institucionais, v. 5, n. 3, 2019.

BUCCI, Maria Paula Dallari; COUTINHO, Diogo. Arranjos jurídico- institucionais da política de inovação tecnológica: uma análise baseada na abordagem de direito e políticas públicas. In: COUTINHO, Diogo; FOSS, Maria Carolina; MOUALEM, Pedro Salomon (orgs.). Inovação no Brasil avanços e desafios jurídicos e institucionais. São Paulo: Blucher, 2017.

COELHO, F. S. A Fase Embrionária do Campo de Públicas: O Processo de Expansão e Diversificação do Ensino de Graduação de Administração Pública no Brasil entre 1995 e 2006. Revista Administração em Diálogo, v. 21, n. 2, 2019, p. 240-267.

GRAU, Eros Roberto. Parecer para Philip Morris Brasil S.A. 1988. Disponível em: <http://bibliotecadigital.fgv.br/ojs/index.php/rda/article/download/47346/45752.> Acesso em: 29 set. 2019.

HAAS, Peter M. Introduction: epistemic communities and international policy coordination. International organization, v. 46, n. 1, 1992, p. 01-35.

KENNEDY, Duncan. The political significance of the structure of the Law School curriculum. Seton Hall Law Review, v. 14, n. 1, 1983, p. 01-16.

MARQUES, Eduardo; FARIA, Carlos Aurélio. A política pública como campo multidisciplinar (coletânea). Rio de Janeiro: Editora Fiocruz, 2013. 
A TAREFA DE ENSINAR DIREITO NO CAMPO DAS POLÍTICAS PÚBLICAS - O DESAFIO DE INTEGRAR UMA COMUNIDADE EPISTÊMICA INTERDISCIPLINAR

MARSHALL, T.H. Cidadania, classe social e status. Rio de Janeiro: Zahar, 1967.

SILVA, Luís Virgílio Afonso da. O proporcional e o razoável. RT, ano 91, n. 798, 2002.

SÃO PAULO. USP. Projeto Político Pedagógico do Curso de Graduação em Gestão de Políticas Públicas (GPP) da Escola de Artes, Ciências e Humanidades da Universidade de São Paulo. São Paulo, 2016. Disponível em:

<http://www5.each.usp.br/wp-content/uploads/2015/11/PPP-GPP-2017.pdf>. Acesso em: 01 out. 2019.

ZITO, A. R. Epistemic communities, collective entrepreneurship and European integration. Journal of European Public Policy, v. 8, n. 4, 2001, p. 585-603. 